\title{
Аргументация процедуры отбора слов-стимулов в рамках проекта «Мультилингвальный ассоциативный тезаурус вежливости»
}

\section{Степыкин Н.И.}

Юго-западный государственный университет, Россия, 305040, г. Курск, 50 лет Октября, 94

E-mail: nick1086@mail.ru

\begin{abstract}
Аннотация. Рассмотрена процедура отбора слов-стимулов для реализации проекта «Мультилингвальный ассоциативный тезаурус вежливости как платформа межкультурной коммуникации и интеграции языковых сообществ», включающая несколько этапов. Первый этап предусматривает проведение компонентного и смежного с ним дефиниционного анализа для выявления структуры и содержания лексемы «вежливость» в русском, английском, итальянском и других языках и последующего добавления выявленных компонентов в список стимульных слов. На втором этапе с целью расширения списка слов-стимулов проводится свободный ассоциативный эксперимент, который выступает эффективным инструментом исследования языкового сознания с учётом его реальных этноспецифических компонентов. Метод интеллекткарт позволяет уточнить и дополнить данные свободного ассоциативного эксперимента. Создание мультилингвального ассоциативного словаря вежливости на основе систематизации ассоциативных данных раскрывает как универсальные, так и этнические и индивидуальные закономерности ассоциативных норм, присущие вербальному ассоциированию носителей различных языков, а также даёт возможность проследить динамику разных по времени фиксации ассоциативных полей.
\end{abstract}

Ключевые слова: ассоциация, ассоциативный тезаурус, вежливость, стимул, реакция.

Благодарности: исследование выполнено при финансовой поддержке Российского фонда фундаментальных исследований (РФФИ) в рамках научного проекта № 20-012-00160 «Мультилингвальный ассоциативный тезаурус вежливости как платформа межкультурной коммуникации и интеграции языковых сообществ».

Для цитирования: Степыкин Н.И. 2020. Аргументация процедуры отбора слов-стимулов в рамках проекта «мультилингвальный ассоциативный тезаурус вежливости». Вопросы журналистики, педагогики, языкознания, 39 (2): 299-305. DOI 10.18413/2712-7451-2020-39-2-299-305

\section{Argumentation of the procedure of selecting cue words in the framework of the project "Multilingual associative thesaurus of politeness"}

\author{
Nikolay I. Stepykin \\ The Southwest State University \\ 9450 Let Oktyabrya St, Kursk, 305040, Russia \\ E-mail: nick1086@mail.ru
}

\begin{abstract}
The article considers the procedure for selecting words-incentives for the implementation of the project " Multilingual associative thesaurus of politeness as a platform for intercultural communication and integration of language communities". The procedure for selecting cues includes several stages. The first stage involves a group of methods related to structural and semantic analysis,
\end{abstract}


component and definition analysis. This allows to identify the content of the word "politeness" in Russian, English, Italian and other languages and then add the obtained components to the list of cue words. At the second stage, in order to expand the list of cue words, a free associative experiment is conducted, which is an effective tool for the study of language consciousness, taking into account its real ethno specific components. For this reason, conducting associative experiments and creating associative thesauri based on them has become one of the leading areas of anthropocentric linguistics. The results obtained using the associative method allow us to identify the structure and content of the associativeverbal network of a native speaker, which has a great heuristic potential in the study of associative norms, i.e. standards in which the semantics of the cue word and the conceptualization of the phenomena behind it are shown to be relevant to the consciousness of native speakers. The method of mind map allows to supplement the data of a free association experiment. The creation of a multilingual associative dictionary based on the systematization of associative data makes it possible to present not only universal, but also ethnic and individual patterns of associative norms inherent in the verbal association of speakers of different languages, and to trace the dynamics of associative fields fixed in different periods of time.

Keywords: association, associative thesaurus, politeness, cue, response.

Acknowledgements: The study was financially supported by the Russian Foundation for Basic Research (RFBR) as part of research project No. 20-012-00160 "Multilingual associative politeness thesaurus as a platform for intercultural communication and integration of language communities".

For citation: Stepykin N.I. 2020. Argumentation of the procedure for selecting stimulus words in the framework of the project "multilingual associative politeness thesaurus". Issues in Journalism, Education, Linguistics, 39 (2): 299-305 (in Russian). DOI 10.18413/2712-7451-2020-39-2-299-305

\section{Введение}

Изучение специфики речевых актов с позиций теории вежливости является одним из актуальных направлений антропоцентрической лингвистики. Работы ученых [Lakoff, 1973; Brown, Levinson, 1978, 1987], инициированные в 1970-1980 гг. ХХ века, стали платформой для развития данной области исследований. На сегодняшний день интерес к категории вежливости не утрачен, о чём свидетельствуют вновь появляющиеся работы по данной проблематике [Sinkeviciute, 2015; Anderson, Huntington, 2017; Haugh, Kádár, 2017; Masullo Chen, Lu, 2017; Alemi, Latifi, 2019; Al Zidjaly, 2019; Ismail, Shanmuganathan, 2019; Isosävi, 2020; Chocron et al., 2020].

Особое внимание следует уделить исследованиям вежливости в русле психолингвистики. Авторы акцентируют психологически релевантное содержание вежливости или невежливости в лексиконе говорящего [Степыкин 2013, 2014; Пищальникова, 2019], установить которое возможно с опорой на ассоциативные нормы. По мнению Дж. Киша [Kishet al., 1972], одного из авторов ассоциативных норм английского языка, ассоциативно-ментальный лексикон человека образует систему поиска информации, управляемую вероятностными процессами в соответствии с характером запроса и активностью того или иного слова.

Повышенный интерес ученых [Stepykin, 2014; Комалова, 2019; Пищальникова, Яо, 2019; и др.] к ассоциативно-вербальной сети как сравнительно новому способу моделирования психологической реальности языка с учётом национально специфических компонентов менталитета вызван осознанием значимости ассоциаций в различных сферах человеческой деятельности. Наиболее эффективным методом при решении этой задачи общепризнанно выступает ассоциативный эксперимент в разных его вариациях (свободный, цепочечный, направленный), направленный на выявление спонтанных реакцийассоциаций, сложившихся у индивида в его предшествующем опыте.

Сбор и фиксация ассоциативных данных, актуализирующих представления современного индивида о вежливости, является одной из первоочередных задач. Мультилингвальный ассоциативный тезаурус вежливости частичнонаправлен на решение обо- 
значенной выше проблемы. Кроме того, предлагаемый проект позволит обнаружить универсальные, индивидуальные и этноспецифические закономерности ассоциативных норм, присущие вербальному ассоциированию носителей различных языков, а также даст возможность проследить динамику разных по времени фиксации ассоциативных полей. При этом объём, валидность и репрезентативность ассоциативных данных в значительной мере зависят от процедуры отбора слов-стимулов для словарных статей ассоциативного тезауруса вежливости. В следующих разделах статьи мы обоснуем эту процедуру на материале русского языка.

\section{Объекты и методы исследования}

Объектом исследования является процедура отбора стимулов для составления словарных статей ассоциативного тезауруса вежливости. Какодин из базовых культурных концептов вежливость формирует образ мира индивида, принадлежащего к определённой лингвокультуре. Для разработки словарных статей ассоциативного тезауруса необходимо установить структурно-содержательную специфику данного феномена. В исследовании предлагается пошаговая процедура отбора стимульных слов, в рамках которой применяются компонентный и дефиниционный анализ, свободный ассоциативный эксперимент (далее САЭ), а также метод интеллект-карт.

В рамках работы над проектом «Мультилингвальный ассоииативный тезаурус вежливости» САЭ проводился в 2020 г., в нём приняли участие 1000 испытуемых, большинство из которых составили студенты. Для распространения бумажных бланков использовались как личные контакты, так и онлайн-форумы и чаты. С целью автоматизации обработки результатов САЭ были применены инструменты Webanketa и Microsoft Office Excel. Информантам было представлено слово-стимул «вежливость» и некоторые другие слова, которые использовались в качестве дистракторов. На третьем этапе был применён метод интеллект-карт. Всего было проанализировано 100 полученных реакций из 10 заполненных интеллект-карт.

\section{Результаты и их обсуждение}

Лексикографические источники фиксируют значение лексемы, поэтому первым этапом процедуры отбора слов-стимулов для мультилингвального ассоциативного тезауруса вежливости является компонентный и дефиниционный анализ. Было установлено, что «лексема вежливость включает следующие компоненты: благовоспитанность, галантность, деликатность, изысканность, корректность, любезность, обходительность, отночения, правила, предупредительность, приветливость, приличие, сочиальньии, тактичность, уважение, уважительность, учтивость, этикет» [Степыкин, 2013]. Это слова-стимулы для проведения свободного ассоциативного эксперимента и фиксации полученных данных в словарных статьях ассоциативного тезауруса.

Однако лексикографические данные отражают состояние языка в определённый исторический момент и не могут учитывать всей специфики вербальной и эмотивной памяти, содержания культурных стереотипов человека и этноса, поэтому для отбора стимулов был применён САЭ. В таблице отражены ассоциации с частотностью более одной реакции респондента.

Рассмотрим единичные ассоциаты на стимул «вежливость»: тактичность, продавеи, внимательность, поведение, королей, привет, корректность, семья, где она? к старшим, горы, полезно, лицемерие, правильно, ложь, приятно, лояльное отношение, с людьми, грамотность, студента, грубость, точность, манеры, персонала, милая, добро, начитанность, понимание, необходима, правда, норма, правильность, образованный, 
принщип, хороший, приятность, черта сильньхх, просто, джентльмен, светский, уступчивость, скучный, высота, драка, открытость, терпение, отличительная черта человека, здравствуйте, отночения, отсутствие, быть вежливым, благодарность, ополаскиватель ласка, чувство, общество, обычно, обязательна.

Реакции на стимул вежливость с частотностью выше 1

Responses to the cue word politeness with a frequency higher than 1

\begin{tabular}{|l|c|}
\hline \multicolumn{1}{|c|}{ Реакции на стимул вежливость } & Количество реакций \\
\hline Учтивость & 21 \\
\hline Воспитанность & 18 \\
\hline Доброта & 14 \\
\hline Воспитание & 11 \\
\hline Уважение & 9 \\
\hline Качество & 5 \\
\hline Обходительность & 5 \\
\hline Было & 3 \\
\hline Культура & 3 \\
\hline Такт & 3 \\
\hline Галантность & 3 \\
\hline Любезность & 3 \\
\hline Порядочность & 2 \\
\hline Люди & 2 \\
\hline Культурность & 2 \\
\hline Улыбка & 2 \\
\hline Поклон & 2 \\
\hline Этикет & 210 \\
\hline Итого & 2 \\
\hline
\end{tabular}

Очевидно, что некоторые из перечисленных выше реакций (2оры, высота, драка и др.) отражают личностные смыслы и не будут включены в контрольный список словстимулов.

Третьим этапом процедуры отбора стимулов стал метод интеллект-карт, который был использован для уточнения и дополнения данных САЭ. Интеллект-карта позволяет установить культурную специфику словарных единиц и семантические связи, которые потенциальны для слова как единицы системы. Приведём пример заполненной интеллекткарты (см. рис.).

Интеграция лексикографических данных, результатов САЭ и интеллект-карт позволяет получить список слов-стимулов для последующего проведения САЭ и составления словарных статей ассоциативного тезауруса вежливости. 


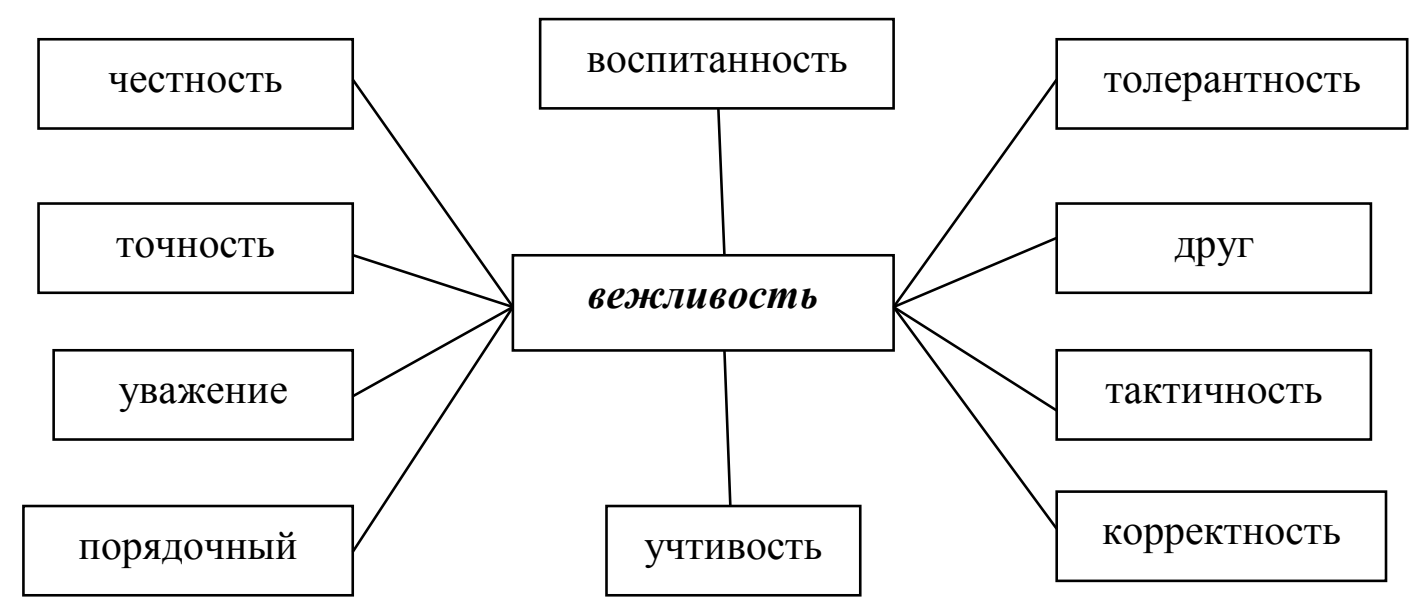

Рис. Интеллект карта «вежливость»

Fig. Mindmap “politeness”

\section{Выводы}

В результате исследования была обоснована трехэтапная процедура отбора словстимулов для составления ассоциативного тезауруса вежливости. На первом этапе был проведён дефиниционный и компонентный анализ лексемы «вежливость», позволивший установить её структуру и содержание. Вторым этапом процедуры отбора стимулов был САЭ, вскрывающий психологически актуальное содержание вежливости. Метод интеллект карт был использован на третьем этапе исследования для уточнения и дополнения данных САЭ.

Интеллект карта даёт возможность установить культурную специфику языковых единиц и семантические связи, которые потенциальны для слова. Аналогичная процедура отбора стимулов может быть использована при работе с английским, итальянским, китайским и другими языками.

Мультилингвальный ассоциативный тезаурус открывает новые перспективные направления в исследовании семантики слова, механизмов речевого воздействия и поведения, в сфере лингвокультурологического поиска.

В ходе анализа ассоциативных данных возможно выявление этнолингвокультурных стереотипов вежливости, что будет способствовать углублению теории межкультурного общения и преодолению языковых и культурных барьеров, что особенно актуально в период грубых и недоброжелательных настроений в современном обществе, так или иначе репрезентированных в языке.

\section{Список литературы}

1. Комалова Л. Р. 2019. Репрезентация вербального образа акта агрессии в информационном универсуме англоязычных СМИ. Вестник Российского университета дружбы народов. Серия: Лингвистика, 23 (1): 149-164. DOI: 10.222363/2312-9182-2019-23-1-149-164.

2. Пищальникова В. А. 2019. Психологически актуальное содержание вежливости в картине мира российских студентов. Человек: образ и сущность. Гуманитарные аспекты, 2 (37): $120-130$.

3. Пищальникова В.А., Чжипэн Яо. 2019. Служить бы рад - прислуживаться тошно, или динамика значения слова 殷勤的 в китайской лингвокультуре. Известия Юго-Западного государственного университета. Серия: Лингвистика и педагогика, т. 9, 1 (30): 56-64. 
4. Степыкин Н.И. 2014. Small Talk: рекомендуемые и конвенционально запрещенные темы (на материале английского языка). Известия Юго-Западного государственного университета. Серия: Лингвистика и педагогика, 4: 25-28.

5. Степыкин Н.И., Мессоре М. 2013. Компонентный анализ лексемы «вежливость» в русском, английском и итальянском языках. Известия Юго-Западного государственного университета. Серия: Лингвистика и педагогика, 4: 93-97.

6. Степыкин Н.И. 2016. Ассоциативное поле: продукт ассоциативного эксперимета и инструмент анализа значения слов. Известия Юго-Западного государственного университета. Серия: Лингвистика и педагогика, 3 (20): 110-116.

7. Alemi M., Latifi A. 2019. The Realization of Impoliteness in Arguments between the Democrats and Republicans over the Government Shutdown Issue in the US. Russian Journal of Linguistics, 23 (1): 83-97. DOI: 10.22363/2312-9182-2019-23-1-83-97.

8. Al Zidjaly N. 2019. Divine impoliteness: How Arabs negotiate Islamic moral order on Twitter. Russian Journal of Linguistics, 23 (4): 1039-1064. DOI: 10.22363/2687-0088-2019-23-4-10391064

9. Anderson A.A., Huntington H.E. 2017. Social Media, Science, and Attack Discourse: How Twitter Discussions of Climate Change Use Sarcasm and Incivility. Science Communication, 39 (5): 598-620.

10. Brown P., Levinson S. 1978. Universals in Language Usage: Politeness Phenomena. Cambridge, Cambridge University Press, 345 p.

11. Brown P., Levinson S. 1987. Politeness. Some Universals in Language Usage. Cambridge, Cambridge University Press, 358 p.

12. Chocron P., Fontaine P., Ringeissen C. 2020. Politeness and Combination Methods for Theories with Bridging Functions. Journal of Automated Reasoning, 64 (1): 97-134. 632.

13. Haugh M., Kádár D. Z. 2017. Intercultural (Im)politeness. London, Palgrave Macmillan, 601-

14. Isosävi J. 2020. Cultural outsiders' reported adherence to Finnish and French politeness norms. Journal of Pragmatics, 155 (1): 177-192.

15. Ismail I.N., Shanmuganathan T. 2019. Face Threats in Threads: Assessing the Responses to Impoliteness in Facebook Comments on 1MDB. 3L: The Southeast Asian Journal of English Language Studies, 25 (4): 34-50.

16. Kish G.R., Armstrong C.A., Milroy R. 1972. An associative thesaurus of English. Wakefield, E.P. Microforms, 267 p.

17. Lakoff R. 1973. The logic of politeness, or minding your p's and q's. Chicago Linguistics Society, 9: 292-305.

18. Locher M.A., Larina T.V. 2019. Introduction to politeness and impoliteness research in global contexts. Russian Journal of Linguistics, 23 (4): 873-903.

19. Masullo Chen G., Lu S. 2017. Online Political Discourse: Exploring Differences in Effects of Civil and Uncivil Disagreement in News Website Comments. Journal of Broadcasting and Electronic Media, 61 (1): 108-125.

20. Sinkeviciute V. 2015. "There's definitely gonna be some serious carnage in this house" or how to be genuinely impolite in Big Brother UK. Journal of Language Aggression and Conflict, 3 (2): $317-348$.

21. Stepykin N.I. 2014. Politeness, courtesy, civility: Mapping associative fields. Journal of Language and Literature, 5 (4): 243-247.

\section{References}

1. Komalova L.R. 2019. Representation of the Verbal Image of Aggression in the Informational Universe of the English-Language Mass Media. Russian Journal of Linguistics, 23 (1): 149 - 164 . DOI: 10.222363/2312-9182-2019-23-1-149-164 (in Russian)

2. Pishchal'nikova V.A. 2019. Psychologically relevant content of politeness in the picture of the world of Russian students. Human being: Image and essence. Humanitarian aspects, 2 (37): 120-130 (in Russian).

3. Pishchal'nikova V.A., Yao Zh. 2019.Serve, Willingly - be Osequious, Never, or Dynamics of the Meaning of the Word 殷勤的 Pleasing in Chinese Language Culture. PROCEEDINGS of the 
SOUTHWEST STATE UNIVERSITY. Series: Linguistics and Pedagogics, Vol. 9, 1 (30): 56-64 (in Russian)

4. Stepykin N.I. 2014. Small Talk: Recommendeded and Conventionally Forbidden Topics (In English). PROCEEDINGS of the SOUTHWEST STATE UNIVERSITY. Series: Linguistics and Pedagogics, 4: 25-28 (in Russian).

5. Stepykin N.I., Messore M. 2013. Component analysis of the lexeme «politeness» in Russian, English and Italian languages. PROCEEDINGS of the SOUTHWEST STATE UNIVERSITY. Series: Linguistics and Pedagogics, 4: 93-97 (in Russian).

6. Stepykin N.I. 2016. Associative Field: the Product of Associative Experiment and an Analysis Tool of the Word's Meaning. PROCEEDINGS of the SOUTHWEST STATE UNIVERSITY. Series: Linguistics and Pedagogics, 3 (20): 110-116 (in Russian).

7. Alemi M., Latifi A. 2019. The Realization of Impoliteness in Arguments between the Democrats and Republicans over the Government Shutdown Issue in the US. Russian Journal of Linguistics, 23 (1): 83-97. DOI: 10.22363/2312-9182-2019-23-1-83-97.

8. Al Zidjaly N. 2019. Divine impoliteness: How Arabs negotiate Islamic moral order on Twitter. Russian Journal of Linguistics, 23 (4): 1039-1064. DOI: 10.22363/2687-0088-2019-23-4-1039-1064

9. Anderson A.A., Huntington H.E. 2017. Social Media, Science, and Attack Discourse: How Twitter Discussions of Climate Change Use Sarcasm and Incivility. Science Communication, 39 (5): 598-620.

10. Brown P., Levinson S. 1978. Universals in Language Usage: Politeness Phenomena. Cambridge, Cambridge University Press, 345 p.

11. Brown P., Levinson S. 1987. Politeness. Some Universals in Language Usage. Cambridge, Cambridge University Press, 358 p.

12. Chocron P., Fontaine P., Ringeissen C. 2020. Politeness and Combination Methods for Theories with Bridging Functions. Journal of Automated Reasoning, 64 (1): 97-134. $601-632$

13. Haugh M., Kádár D.Z. 2017. Intercultural (Im)politeness. London, Palgrave Macmillan,

14. Isosävi J. 2020. Cultural outsiders' reported adherence to Finnish and French politeness norms. Journal of Pragmatics, 155 (1): 177-192.

15. Ismail I.N., Shanmuganathan T. 2019. Face Threats in Threads: Assessing the Responses to Impoliteness in Facebook Comments on 1MDB. 3L: The Southeast Asian Journal of English Language Studies, 25 (4): 34-50.

16. Kish G.R., Armstrong C.A., Milroy R. 1972. An associative thesaurus of English. Wakefield, E. P. Microforms, 267 p.

17. Lakoff R. 1973. The logic of politeness, or minding your p's and q's. Chicago Linguistics Society, 9: 292-305.

18. Locher M. A., Larina T. V. 2019. Introduction to politeness and impoliteness research in global contexts. Russian Journal of Linguistics, 23 (4): 873-903.

19. Masullo Chen G., Lu S. 2017. Online Political Discourse: Exploring Differences in Effects of Civil and Uncivil Disagreement in News Website Comments. Journal of Broadcasting and Electronic Media, 61 (1): 108-125.

20. Sinkeviciute V. 2015. "There's definitely gonna be some serious carnage in this house" or how to be genuinely impolite in Big Brother UK. Journal of Language Aggression and Conflict, 3 (2): $317-348$.

21. Stepykin N.I. 2014. Politeness, courtesy, civility: Mapping associative fields. Journal of Language and Literature, 5 (4): 243-247.

\section{ИНФОРМАЦИЯ ОБ АВТОРЕ}

Степыкин Николай Иванович, кандидат филологических наук, зав. кафедрой теоретической и прикладной лингвистикифакультета лингвистики и межкультурной коммуникации Юго-западного государственного университета, г. Курск, Россия

\section{INFORMATION ABOUT THE AUTHOR}

Nikolay I. Stepykin, candidate of philological sciences, head. Department of Theoretical and Applied Linguistics, Faculty of Linguistics and Intercultural Communication, Southwestern State University, Kursk, Russia 